\title{
EL PROBLEMA DE LA TÉCNICA: EL HOMO FABER, LA MÍSTICA Y LA DECADENCIA. CULTURA MAQUINISTA EN OSWALD SPENGLER Y HENRI BERGSON
}

\author{
ÁLVARO CORTINA URDAMPILLETA \\ Universidad Diego Portales / Leiden University
}

\begin{abstract}
RESUMEN: Este artículo ofrece una visión paralela sobre el problema de la técnica de Oswald Spengler y de Henri Bergson, autores de El hombre y la técnica. Una contribución a la filosofía de la vida y Las dos fuentes de la moral y de la religión, respectivamente. En general, el trabajo se centra en estos dos ensayos para dar cuenta de los puntos en común y de la distancia entre estos dos pensadores. El texto está dividido en tres apartados. Uno muestra sus respectivas visiones antropológicas en relación con el problema de la técnica, a continuación, comenta afinidades y desencuentros en relación a su interpretación histórica de la cuestión del maquinismo, y, en tercer lugar, se habla de la cuestión más relativa al contexto histórico de estas dos contribuciones al tema que aquí nos ocupa. ¿En qué medida es para ambos la técnica un signo de decadencia o no? En este último punto, la perspectiva fatalista de Spengler se separa de la bergsoniana.
\end{abstract}

PALABRAS CLAVE: Bergson; Spengler; técnica; decadencia; homo faber; mística.

\section{The problem of technique: homo faber, mysticism and decadence. Machinist culture in Oswald Spengler and Henri Bergson}

ABSTRACT: THIS article offers a compared analysis of the problema of technology in Oswald Spengler and Henri Bergson, authors of Man and technics and The two sources of morals and religión, respectively. In general, this paper is focused on the main topics of agreement and the main philosophical divergences between both. This is a threefold text. Section 1, shows the different anthropological visions held by these two authors, so related to the topic of technology since both are defenders of the definition of humans as homo faber. Secondly, I show the different historical interpretations of the problem of technics (origins and specificity of the Western phenomenon of technology). In the end, I reach to the historical context of these two books. Is technology a symbol of the decadence of modernity? At this point, the fatalist Spenglerian position is opposite to the Bergsonian one.

KEY WORDS: Bergson; Spengler; technology; decline; homo faber; mystic.

\section{INTRODUCCIÓN}

Los ensayos El hombre y la técnica. Una contribución a la filosofía de la vida, de Oswald Spengler, y Las dos fuentes de la moral y de la religión, de Henri Bergson, escritos en 1931 y en 1932, respectivamente, exponen dos aproximaciones filosóficas al problema de la técnica o cultura del maquinismo occidental. Este asunto concreto orienta en buena medida el conjunto de la filosofía de la historia de estos autores, en especial, en la segunda etapa de sus respectivas carreras. En La technique, JeanPierre Séris ${ }^{1}$ considera las perspectivas de Spengler y de Bergson como opuestas.

1 Capítulo 4, «Techniques et machines». 
La disparidad se puede resumir en que, según el comentador, Spengler es pesimista y Bergson optimista con respecto al papel de la técnica o cultura maquinista en la modernidad. En este artículo voy a matizar esas diferencias, que no tienen que ver únicamente con un presunto optimismo o pesimismo, y en consecuencia, voy a resaltar también las importantes afinidades entre Spengler y Bergson.

Ambos consideraron que el maquinismo ha de ser puesto en relación con la antropología filosófica, aunque sus respectivas antropologías filosóficas sean distintas, pese al indudable aire de familia entre ellas. En este punto, la técnica está relacionada con la inteligencia y es un producto de la naturaleza biológica humana. Son dos filósofos que conciben al homo sapiens como homo faber, su esencia es técnica y fabricadora. Ambos acercamientos al tema comienzan con un estudio de las sociedades primitivas, según las fuentes antropológicas de la época. Hablaré de esta cuestión en la primera sección del escrito.

A continuación, intentaré dar cuenta del papel del maquinismo en ambas filosofías de la historia de Occidente, pues tanto el alemán como el francés lo consideraron un elemento central, y además, más allá de la antropología, un impulso peculiar de la cultura de Occidente. En este punto, Spengler y Bergson sostienen que la técnica occidental, aunque basada en el sustrato natural que veremos en el primer epígrafe, recibe un impulso nuevo. La técnica Occidental es sustancialmente diferente de la técnica de otras culturas como la antigua o las culturas orientales. Este impulso inédito está, para los dos pensadores, relacionado con la mística. Spengler considera desde La decadencia de Occidente que el maquinismo tiene sus fuentes en el Alto Medievo y atraviesa la modernidad. La técnica moderna tiene que ver con el sentimiento «fáustico». En El hombre y la técnica, aunque sustancialmente diferente de su famoso ensayo largo, se mantiene en su anterior posición y desarrolla esta idea. Para Bergson, por usar sus términos, «el espíritu de invención» se une a la «ciencia» y a la «mística» un impulso, de nuevo ligado a una nueva ideología, en la modernidad, en el siglo XV y XVI. La ciencia aporta a la técnica un impulso progresivo descomunal. La mística aporta a la técnica un sentido también progresivo pues, según él, funda la democracia moderna. La técnica emancipa al hombre en general.

En la tercera sección de mi escrito abordo la cuestión del optimismo y el pesimismo ya mencionada. Spengler considera que la técnica, en términos generales, no exclusivamente, es un signo de decadencia. Además, el caso de la técnica, como he dicho, es peculiarmente importante en el caso de la cultura occidental. De aquí infiero que su decadencia es doble. La postura de Bergson es esencialmente ambivalente, y tiene mucho que ver con su visión general de la filosofía de la historia. Tiene mucha razón la estudiosa italiana Caterina Zanfi cuando en su monografía titulada Bergson, la técnica, la guerra, ${ }^{2}$ hablaba sobre la tendencia negativa de Bergson con respecto al maquinismo. Al mismo tiempo, como espero mostrar, su tono es más bien esperanzado. Esta esperanza constituye una diferencia importante entre las dos visiones de los dos filósofos. Aunque desde $\mathrm{La}$ decadencia de Occidente Spengler defiende que las diferentes culturas de la historia (Clásica, Fáustica, Mágica, etc.) nacen de una manera espontánea, sus estadios

\footnotetext{
2 Bolonia University Press, 2009.
} 
(primavera, verano, otoño y decadencia) están determinados. En su ensayo en dos volúmenes de 1918 y 1922 Spengler incluso calcula mil años de vida para cada cultura. Cada cultura, además, está abocada a la decadencia, exactamente igual que un organismo. Esta teoría, como digo, se expone en La decadencia de Occidente y se retoma, años después, en El hombre y la técnica, donde, por cierto, y esto supone una diferencia importante, el tema de la relatividad de las culturas se deja de lado. Parece que el relato de Spengler pasa a ser un relato universal, que pasa del hombre primitivo al declive del hombre fáustico en una línea única de progreso. El tema principal de este libro es la lucha del hombre frente a la naturaleza y el tono general de la conclusión parece más apocalíptico si cabe que el de 1922 (ver John Farrenkopf, 2001). La libertad humana no tiene ninguna capacidad de frenar la decadencia que la técnica o maquinismo representa.

Bergson tiene una posición diferente, y seguramente lo más alejado de Spengler que puede encontrarse en su ensayo de ancianidad es que, por una parte, aunque la máquina representa la decadencia de hecho, no la representa de derecho. Todo depende del uso que le de el hombre. Todo depende de la libertad humana, dice. Bergson tiene una visión muy positiva de la técnica y de su poder emancipador, y tal era su cometido en origen. Bergson tampoco pasa por alto su contribución nefasta a la decadencia de las costumbres occidentales y su papel en la industrialización amenazante de la guerra. En comparación con otros autores, como Spengler, la postura de Bergson es positiva. Además, y por último, desde mi punto de vista en el texto de 1932 de Bergson hay una tensión entre democracia y aristocracia. En el último capítulo de su libro, «Mecánica y mística» el autor parece pretender una reforma de las costumbres del hombre medio europeo, pero además parece que el verdadero progreso sólo puede llegar de la mano de un aristócrata, de un creador de valores.

\section{Máquina y mentalidad PRIMitiva}

Tanto Spengler como Bergson consideran oportuno remontarse al origen del hombre para llegar a la raíz del problema. Ambos sostienen una visión pragmatista de la inteligencia humana: conceptos y relaciones intelectuales están diseñados para operar sobre el mundo. Frente al homo sapiens, ambos defienden el término homo faber, hombre constructor.

Spengler atribuye una suerte de «técnica» al reino animal en general. En especial, hace hincapié en la más sofisticada técnica de determinados animales predadores. Técnica es pues «estrategia» instintiva, para el alemán. Para este nietzscheano el homo faber es un animal de presa, un depredador, un «Raubtier». La técnica plasma la voluntad de poder del ser vivo sobre el medio. Pero la técnica del hombre queda implícitamente resaltada, según Spengler, por su extraordinaria contingencia: la aparición de la mano (se sobreentiende que la mano que ha perfeccionado la capacidad de "hacer pinza» con el pulgar) supone la aparición de la humanidad. La mano humana ofrece así a la inteligencia infinitas posibilidades de actuación, una capacidad técnica que no es relativa a un medio ambiente concreto. Mano y cerebro son la base de la humanidad, según Spengler, quien, frente a lo que él entiende por darwinistas, defiende que ambas aparecieron de una manera brusca (apoyándose 
en el mutacionismo de De Vries). La humanidad aparece como constructora. La mano es el emblema del homo faber. Aunque Spengler no lo aclara, parece que entre la «técnica» entendida como "táctica», extensible a todos los animales, y la «técnica» entendida como "actividad intelectual-manual», sólo aplicable al caso humano, hay un salto de naturaleza y no de grado.

Spengler establece una segunda fase proto-histórica, en su capítulo 4 («Die zweite Stufe: Sprechen und Unternehmen»), la aparición del lenguaje. Se trata de una fase social o comunitaria. En este origen mítico que Spengler plantea, los hombres renuncian a su vida solitaria unifamiliar para ser más poderosos. El lenguaje supone, según Spengler, la ampliación de esa «actividad intelectualanimal»: el lenguaje implica un aumento de la operatividad y sofisticación del hombre sobre la naturaleza ${ }^{3}$.

Spengler parece sugerir un «estado de naturaleza» sucedido por un estado de cultura, en el que el hombre establece una comunidad y se relaciona para ser más fuerte así.

Ya en 1907, en La evolución creadora, Bergson defiende también una visión de la evolución como esencialmente discontinua, también apoyándose en De Vries, está de acuerdo en que i) la cultura actual y la prehistoria tienen un elemento técnico asimilable y en ii) que la inteligencia humana y el instinto animal tienen un común origen en la vida que no habría que pasar por alto. La inteligencia busca el dominio a través de la predicción (las leyes sirven para predecir) y su origen es práctico, aunque después se transforme en ciencia. La mano, nuevamente, es una expresión de la falta de especialización del hombre, de la contingencia de la especie humana ${ }^{4}$.

Pero contra Spengler, Bergson destaca la naturaleza cualitativamente diversa de la inteligencia. En Bergson el hombre nunca ha sido solitario y, sucesivamente, social. Como otros animales sociales, el hombre comenzó en grupo. Según Bergson, técnica y sociedad aparecieron en el hombre al mismo tiempo. Es decir, Bergson no establece dos fases de la humanización. El origen del hombre es fabricación de artificios $^{5}$, y comunidad, una comunidad "cerrada», como trata en Las dos fuentes de la moral y de la religión.

Como en el mito de Prometeo (Protágoras 320d-322d), según Platón, las artes técnicas y el fuego llegan a los hombres en reparto desigual (321d) y éstos desarrollan solos, a partir de las técnicas y del fuego, el lenguaje (322a). Pero hace falta, nos cuenta Protágoras, que Hermes, enviado por Zeus, baje después de la venida del titán Prometeo a repartir indistintamente la justicia y la ciencia política (donde está incluido el arte de la guerra) entre los todos hombres.

Por mantenerme en estos términos míticos, en la visión de Spengler de su capítulo 4, existe una "segunda venida» de los dioses a la tierra que aporta igualmente el lenguaje, porque es lo más parecido a la justicia que él entiende: una visión más ampliada de la misma voluntad de poder. Spengler establece una distinción cualitativa entre la técnica individual (mano) y la común (lenguaje). Para Bergson sólo existe una «venida» de Prometeo: el símbolo. Como en el mito que narraba el sofista a Sócrates, a partir de las artes técnicas encontramos el lenguaje.

3 Jankélévich destaca la arbitrariedad de estas dos etapas, JANKÉLÉVICH (1934) 329

4 Bergson, L'évolution créatrice, 2009, 134.

5 Ibid, 138. 
En Bergson, la posesión de la racionalidad implica un dominio del símbolo, y este dominio simbólico de los útiles implica también una referencia social. ${ }^{6}$ No habría pues para el francés un estadio de naturaleza pre-social. Para Bergson el hombre primitivo nace en sociedad, una sociedad cerrada. Históricamente se desarrollaría la segunda sociedad, la sociedad abierta, que es más bien una «tendencia social» hacia el progreso cosmopolita.

\section{Máquina y Occidente}

El último capítulo de El hombre y la técnica. Una contribución a la filosofía de la vida tiene como epígrafe «El final: ascenso y término de la cultura maquinista», y allí se propone un «espíritu maquinista», de origen místico y ascético. Los «piadosos frailes $»^{7}$ entre los que señala a Witelo, Roger Bacon o Nicolás de Oresme, "creían que lo que querían era conocer a Dios, pero lo que en realidad querían era aislar, hacer utilizables, palpables, las fuerzas de la naturaleza inorgánica» ${ }^{8}$. Este germen medieval se desarrolla plenamente a lo largo del renacimiento y la modernidad hasta el siglo XIX, donde aparece la figura de lo que, en 1922 ya llamó, el «sabio sacerdote de la máquina» ("der wissende Priester der Machine» ${ }^{9}$ ).

Como ya sostenía el autor alemán en el apartado final del segundo volumen de La decadencia de Occidente, se puede hablar de un "espíritu de la máquina» ${ }^{10}$, y el maquinismo pasa a ser, más y más explícitamente en la historia de la modernidad, un culto. Se podría, según él, hablar de una «historia de la técnica europea».

A Séris no se le escapa la similitud de este capítulo de Spengler y con el epígrafe "Mecánica y mística», que cierra Las dos fuentes de la moral y de la religión. Escribe Bergson:

«La máquina no ha dado todo su rendimiento hasta el día en que ha sabido poner a su servicio, por un simple mecanismo, energías potenciales almacenadas durante millones de años, debidas al sol, depositadas en la hulla, el petróleo, etc. Ahora bien, este día fue el de la invención de la máquina de vapor, y es sabido que no se debió a consideraciones teóricas. Apresurémonos a añadir que el progreso, en un comienzo lento, se ha efectuado a pasos de gigante desde el momento en que la ciencia le ha prestado su ayuda. No es menos cierto que el espíritu de invención mecánica, que se deslizó por un cauce estrecho mientras estuvo abandonado a sí

6 Recordemos que Prometeo sólo nos trajo técnica, y que de esa técnica aparece, naturalmente, el lenguaje. El símbolo que la inteligencia nos aporta es útil porque es traducible, es compartible. El símbolo es comunitario. «Sýmbolon», en griego, se puede traducir como señal, signo o emblema, pero el diccionario también contempla que designe contratos, convenciones o tratados de comercio. Aun tomado a solas, el hombre bergsoniano tiene una inteligencia social. El yo profundo y el yo social están relacionados ya en el ciudadano, en medio de la ciudad amurallada, ya en el corazón del naufrago solitario. Sin la sociedad, nos dice Bergson, al hombre le consume el tedio". Las dos fuentes de la moral y de la religión, desde ahora DS, p. 109.

7 Spengler, O. Der Mensch und die Technik. München 1931, p. 69.

8 Ibíd., p. 67.

9 Spengler, O. Der Mensch und die Technik. München 1931, p. 70-71.

10 SPENGLeR, O. 1922, 624. 
mismo, y que se ensanchó indefinidamente cuando se unió a la ciencia, sigue siendo distinto de ésta y podría en rigor separarse de ella. También el Ródano entra en el lago de Ginebra y parece mezclar con él sus aguas, pero cuando sale demuestra haber conservado su independencia» ${ }^{11}$.

Este otro texto completa la genealogía de la técnica moderna expresada en Las dos fuentes de la moral y de la religión:

«No es cuestionable que los primeros esbozos de lo que más tarde sería el maquinismo, se dibujaron al mismo tiempo que las primeras aspiraciones a la democracia. El parentesco entre las dos tendencias se hace plenamente visible en el siglo XVIII, y es sorprendente en los enciclopedistas. Por consiguiente, ¿no debemos suponer que fue un aliento democrático lo que empujó adelante el espíritu de invención, tan viejo como la humanidad, pero insuficientemente activo hasta que no se le concedió atención preferente» ${ }^{12}$.

En el primero de estos dos textos, Bergson refiere la unión de una suerte de espíritu de invención mecánica y la ciencia moderna. En el segundo, el aliento democrático. Para Bergson, esta aspiración democrática es profundamente humanística y converge con el espíritu evangélico. La técnica tiene que ver con la ciencia moderna y la técnica tiene que ver con una suerte de mística, o de espíritu de progreso, lo que él llama «sociedad abierta».

Tanto para Spengler como para Bergson, la «cultura de la máquina» o «espíritu de invención» son elementos esenciales en la historia de Occidente. Para Spengler está ligado a la idea de civilización, es decir, a la fase de madurez y de decadencia de las culturas, del mismo modo que el economicismo o las megalópolis. Además, la técnica es algo que se da de una manera muy especial en la cultura fáustica y aparece en el inicio de ésta, en la Alta Edad Media. Se puede extraer de su breve tratado de 1931 que el hombre de la cultura occidental o fáustica desarrolla de una manera sin igual un carácter del hombre primitivo, del hombre sin cultura. Además, esta visión de la técnica, hemos visto, está relacionada con una mística.

La interpretación de Bergson es menos ambiciosa o más convencional, pues relaciona la ciencia moderna con la mística moderna, y a éstas con el espíritu de invención o técnica, cuyo auge está en la revolución industrial del XVIII.

Mística y ciencia son la base de la técnica, según estos dos autores. Lo principal de su acuerdo reside en que son dos filosofías de raíz cristiana las que transforman la visión de la naturaleza. La naturaleza es vista ahora como una suerte de taller donde se puede aplicar los conocimientos científicos para emprender la nueva empresa de la dominación técnica.

\section{Máquina y decadencia}

Spengler plantea que el fin de Occidente, la decadencia, se consuma cuando la máquina se adueña del destino del hombre. El hombre pasa a servir a la máquina (según la figura del trabajador, del ingeniero y del empresario, según explica en el

11 DS, 325. El subrayado es mío.

12 DS, 329. 
último capítulo de La decadencia). La democracia, según Spengler, es la perfecta descripción del hombre desde el punto de vista de la técnica: la comunidad como un todo mensurable cuantitativo. La democracia es la cultura del número. Para Spengler la democracia es pura decadencia y va unida a la "Maschinenkultur», en el sentido de que, de algún modo, en el «imperio de los muchos» se deposita el poder en la técnica. La democracia expresa la tendencia de una cultura hacia lo cuantitativo.

La producción en serie de lo idéntico, el hombre masa desarraigado, el dinero, la ciudad, el imperio del dinero son rasgos de la decadencia de una cultura, la esencia de lo que llama civilización.

La democracia es para Bergson, al contrario, el triunfo del espíritu, de la mística cristiana. Para Bergson hay una tendencia universal al progreso, idea que Spengler rechaza. Para Bergson, esa tendencia es la "sociedad abierta», y la trata en el capítulo 3 de Las dos fuentes de la moral y de la religión. La democracia es la principal expresión de esta tendencia de origen evangélico.

Pero, a pesar de esta descripción general de la historia universal, que culmina en la democracia, en Bergson, he dicho ya, se detecta una clara ambivalencia. En el último capítulo de Las dos fuentes de la moral y de la religión, Bergson refiere una suerte de decadencia. Bergson parece proponer un retorno a la vida ascética medieval, una huida del placer del lujo, de la procreación desmedida. ${ }^{13}$ También menciona el privilegio con el que la civilización técnica favorece a las ciudades sobre el medio rural ${ }^{14}$. Esta suerte de prédica de Bergson, sólo se en entiende en un contexto de clara decadencia occidental.

Como el planteamiento de Spengler es fatalista, y según su concepción, la democracia y el maquinismo están necesariamente unidos, la conclusión de su visión histórica no puede ser positiva. El hombre está abocado a sucumbir al imperio de la máquina, aunque no ofrece demasiados detalles al respecto. De una manera u otra, la técnica, nos dice Spengler es la perdición del hombre. Además, añade, el tiempo del arte y de las humanidades de la cultura, de la verdadera «creación» fáustica ha pasado. Ahora (año 1931), parece decir, es el tiempo de la ingeniería.

El planteamiento de Bergson es ambivalente, pues la técnica no ha mejorado la calidad de vida de los hombres, ni, sobre todo, su calidad moral. En un momento que no especifica, según Bergson, ciencia y mística se separaron. Bergson se refiere a la técnica como un «cuerpo agrandado» que espera un «suplemento de espíritu». Bergson se refiere a líderes espirituales que aporten un «élan» humanístico a la

13 Cuando Bergson confronta en DS, su teoría con la de Ernest Seillière en Mysticisme et domination. Essai de critique impérialiste, de 1913, considera con otras palabras, creo yo, que no se debería confundir la expansión técnica con la mística, a pesar de que la técnica tenga algo de mística. El imperialismo, dice Bergson, no es un misticismo (DS, 331). Es, simplemente, una formación de tendencia patriótica (primera fuente de la moral y de la religión) disfrazada de mística (segunda fuente) por su intención de conquistarlo todo. El ansia de totalidad, de universalidad dirige al imperialismo, pero desde la perspectiva concreta de una dominación política. Esto es un «falso misticismo verdadero», según Bergson, pues tergiversa la verdad de un anhelo profundo con propósitos materiales.

14 DS, 327. Esto tiene un cierto regusto a «desarraigo» spengleriano, pues, entre otras cosas, el alemán describe la decadencia como la victoria de la gran ciudad frente a las provincias. 
altura de los tiempos. Los líderes, las personas ejemplares o como he dicho más arriba, los héroes del espíritu son la esperanza de Bergson.

Además, en Bergson está la cuestión del pacifismo, tan ajena a Spengler. La Guerra Mundial fue para Bergson un ejemplo de lo que es la técnica moderna al servicio de la guerra, atavismo fundado en nuestra naturaleza instintiva o animal. Bergson se pregunta si, del mismo modo en que la técnica ha cambiado la idea de guerra por algo más terrorífico, puede hacer de la paz algo más sólido, más enriquecedor para todos los ciudadanos.

En su texto, Bergson pretende promover un cambio de costumbres del hombre medio hacia la austeridad. Además, su escrito refleja el mencionado anhelo mesiánico. Entre el discurso para el hombre medio y la esperanza del mesías está la tensión que mencioné entre democratismo bergsoniano y aristocratismo vitalista. El texto de Spengler es descreído. Nuestro tiempo es el que nos ha tocado. Debemos contemplarlo y estar firmes y despiertos. Spengler apela, con su característico tono militar y trágico a una suerte de afirmación frente al destino ${ }^{15}$.

\section{CONCLUSIÓN}

En este trabajo he querido mostrar afinidades y diferencias en tres planos diferentes. Por un lado, hemos visto cómo la técnica moderna, entendido como maquinismo, es la deriva de un rasgo específico humano, de gran peso en las antropologías de Spengler y de Bergson, filósofos del homo faber. En el alemán, la técnica y la comunidad aparecía en dos estadios antropológicos diferentes y sucesivos. En el francés, técnica y comunidad surgían de la "sociedad cerrada». Esto, he señalado, se ilustra bien con el relato platónico del Protágoras, en torno al mito de Prometeo, donde se habla de dos «venidas» sucesivas de los dioses al hombre y de dos estadios antropológicos: el estadio de la técnica y el estadio comunitario (justicia, etc). Spengler se ajusta al relato de Protágoras en el diálogo de Platón y Bergson, sin embargo, defiende un solo estadio antropológico.

De acuerdo con su propia teoría histórica expuesta en La decadencia de Occidente, Spengler encuentra las raíces de la técnica moderna en la Alta Edad Media. Bergson, en cambio, en la modernidad, en los siglos XVI, XVII, cuyo auge está en la primera revolución industrial. En el caso de Bergson, la técnica comenzó ligada a una tendencia progresiva. En Spengler, en cambio, no hay tendencias progresivas en sentido estricto. Ambos identifican la técnica con una nueva cosmovisión occidental y con una mística. Esta mística supone un añadido inconmensurable a la técnica primitiva de la que hablamos antes. Ambos autores hablan sólo de estos dos estadios técnicos, a cada extremo del decurso histórico universal del hombre.

15 «Wir sind in diese Zeit geboren und müssen tapfer den Weg zu Ende gehen, der uns bestimmt ist. Es gibt keinen andern. Auf dem verlorenen Posten ausharren ohne Hoffnung, ohne Rettung, ist Pflicht. Ausharren wie jener römische Soldat, dessen Gebeine man vor einem Tor in Pompeji gefunden hat, der starb, weil man beim Ausbruch des Vesuv vergessen hatte, ihn abzulösen. Das ist Größe, das heißt Rasse haben. Dieses ehrliche Ende ist das einzige, das man dem Menschen $\mathrm{n}$ i c h t nehmen kann». Spengler, Der Mensch und die Technik. München 1931, p. 89. 
La última cuestión retoma la distinción de Séris entre la visión optimista y la pesimista de la técnica. En el caso de Spengler, como dice el comentador francés, la perspectiva es pesimista, pues está ligado a la decadencia de Occidente. Además, su fatalismo prescribe que no habría la posibilidad de hablar de una técnica en términos positivos o de invertir la situación del Occidente que él percibe a principios de los años 30.

Raymond Aaron ha llamado la atención sobre la peculiar idea de Historia que tiene Bergson: es una filosofía sin leyes históricas. La idea de técnica en Bergson es positiva, pero esto no es algo necesario, sino contingente. Esta idea se fue volviendo cada vez más pesimista, en especial a causa de la Primera Guerra Mundial. La idea positiva de la técnica del Bergson de La evolución creadora se mezcla con las ideas más negativas del Bergson de los «discursos de guerra», como llamó Soulez a su obra propagandística entre 1914 y 1919. La visión de la técnica de Bergson hacia 1932 no es positiva, es, como adelanté más arriba, ambivalente. De hecho, el maquinismo occidental ha promovido una suerte de decadencia. Esta decadencia no estaba predeterminada, como en Spengler, sino que ha sido, más bien, una desviación. En Spengler todo depende de sus leyes históricas organicistas, en Bergson no existen tales leyes, la historia no se puede predecir. La visión general de Spengler es cíclica, y nada se sale de estos ciclos. En Bergson, la historia es una sucesión de divergencias o dicotomías.

Los capítulos «El final: ascenso y término de la cultura maquinista», del libro Spengler, y «Mecánica y mística», del último título extenso de Bergson, son obras afines. La técnica o maquinismo es el problema central en ambas. Spengler reclama una suerte de actitud estoica, afirmativa, frente a un inexplicado pero sugerido apocalipsis. El texto Bergson también tiene la marca de un tiempo convulso. La posibilidad del apocalipsis es también mencionada. Pero este Bergson convertido después de 1914 en intelectual de alcance social, pide una reforma de las costumbres y no olvida el carácter promisorio original de la técnica. Advierto en su escrito ciertos rasgos mesiánicos. El gran hombre de nuestro, tiempo, parece querer decir, está por llegar. El escrito de Bergson no es positivo en el sentido en que el de Spengler es negativo. Bergson no es Spengler... pero tampoco es Spencer. El futuro, bueno o malo, es impredecible. No hay ley histórica que anule la posibilidad del ser humano de crearse a sí mismo, es decir, de ser libre. Bergson tan sólo asegura que la técnica tendrá un papel decisivo en ese porvenir.

\section{BiBLIOGRAFÍA}

Aaron, R. (1956). «Note sur Bergson et l'histoire». Études bergsoniennes, IV, p. 41-51.

Bergson, H. (2008). Les deux sources de la morale et de la religion. Paris: (DS) PUF.

- (2009). L'évolution créatrice. Paris: PUF.

- (1972). Mélanges. Paris: PUF.

Farrenkopf, J. (2001). Prophet of Decline: Spengler on world history and politics. Baton

Rouge: Louisiana State University Press.

Jankélévich, V. (2008). Bergson. Paris: PUF.

- (1934).«L'homme et la technique (À propos d'un noveau libre d'Oswald Spengler)». Europe.

- (1933). «Les deux sources de la morale et de la religion d'après M. Bergson», Revue de métaphysique et de morale. 
Keck, F. (2002). «Bergson et l'anthropologie, le problème de l'humanité dans "Les deux sources de la morale et de la religion"». Annales bergsoniennes, vol. I. PUF.

Plato (1902). Platonis Opera. Oxford: Oxford Classical Texts.

Séris, J.-P. (1994). La technique. Cap. IV. «Techniques et machines». Paris: PUF.

Ondřej Švec (2012). «La fragilité de la démocratie face au défi de la technique». Annales bergsoniennes. Vol V. Paris: PUF.

Soulez, P. (1989). Bergson politique. Paris: PUF.

Spengler, O. (1931). Der Mensch und die Technik. München: Beck'sche Verlagsbusch handlung. - (1922). Der Untergang des Abendlandes. Band. II. München: Beck'sche Verlagsbusch handlung.

Zanfi, C. (2009). Bergson, la tecnica, la guerra. Bolonia: University Press.

Universidad Diego Portales / Leiden University

Álvaro Cortina URDAmpilleta

alvarocortina@hotmail.com

[Artículo aprobado para publicación en diciembre de 2016] 